\title{
Identification of Four Wood Species by an Electronic Nose and by LIBS
}

\author{
Juliana R. Cordeiro, ${ }^{1}$ Maria I. V. Martinez, ${ }^{2}$ Rosamaria W. C. Li, ${ }^{1}$ \\ Anderson P. Cardoso, ${ }^{1}$ Lidiane C. Nunes, ${ }^{3}$ Francisco J. Krug, ${ }^{3}$ Thiago R. L. C. Paixão, ${ }^{1}$ \\ Cassiana S. Nomura, ${ }^{1}$ and Jonas Gruber ${ }^{1}$ \\ ${ }^{1}$ Instituto de Química, Universidade de São Paulo, Avenida Professor Lineu Prestes, 748, 05508-900 São Paulo, SP, Brazil
${ }^{2}$ Centro de Ciências Naturais e Humanas, Universidade Federal do ABC, Rua Santa Adélia, 166, 09210-170 Santo André,
SP, Brazil
${ }^{3}$ Centro de Energia Nuclear na Agricultura, Universidade de São Paulo, Avenida Centenário 303, 13416-000 Piracicaba, SP, Brazil
}

Correspondence should be addressed to Jonas Gruber, jogruber@iq.usp.br

Received 26 September 2011; Revised 5 November 2011; Accepted 10 November 2011

Academic Editor: Abel César Chialvo

Copyright (C) 2012 Juliana R. Cordeiro et al. This is an open access article distributed under the Creative Commons Attribution License, which permits unrestricted use, distribution, and reproduction in any medium, provided the original work is properly cited.

This paper presents two complementary methods capable of identifying four wood species (Cedrela fissilis, Ocotea porosa, Hymenolobium petraeum, and Aspidosperma subincanum) both by their volatile organic compounds and by the presence of 10 chemical elements: $\mathrm{Al}, \mathrm{B}, \mathrm{Ca}, \mathrm{Mg}, \mathrm{Zn}, \mathrm{Cu}, \mathrm{Mn}, \mathrm{Fe}, \mathrm{Na}$, and $\mathrm{Si}$. The volatile compounds were detected by an electronic nose formed by an array of three different conductive polymer gas sensors. The elemental determination was made by laser-induced breakdown spectrometry (LIBS). The emissions measured were treated by principal component analysis (PCA). Leave-one-out analysis showed a rate of hits of $100 \%$.

\section{Introduction}

The identification of wood has become an important issue lately due to environmental concerns, since a growing number of species are endangered and should no longer be freely commercialized [1]. The traditional wood identification processes are cumbersome and cannot be performed in loco since they usually involve anatomical, histological, or structural analyses, such as scanning electron microscopy (SEM) [2] and near-infrared (NIR) spectroscopy [3], requiring the presence of a highly trained professional.

We have recently described chemiresistive gas sensors, based on conductive polymers, for sensing several organic solvents [4], low-molecular-weight alcohols [5, 6], and volatile halogenated organic compounds (VHOCs) [7] and also for determining alcohol content in automotive fuel [8]. An array of gas sensors connected to a pattern recognition software is known as electronic nose [9] and can analyse complex mixtures of volatile compounds. Although the most common commercial sensors are made of metal oxide semi- conductors (MOSs), recently, conductive polymer-based sensors are becoming more popular because they operate at room temperature, have low power consumption, and offer a wide range of structural variations, which leads to more selective sensor arrays.

Among others, atomic spectrochemical techniques have also allowed the identification, classification, and fingerprinting of products, such as coconut water [10], wine [11], and orange juice [12]. It is known that elemental determination is not trivial and in most cases requires sample decomposition before the analysis. Laser-induced breakdown spectrometry (LIBS) has deserved attention due to the possibility to perform a multielemental determination and direct analysis even in solid samples. Godoi et al. [13], for instance, used the LIBS system for the classification of toys relying on toxic elements. The portable characteristic of this technique makes it useful for in situ analyses, and it has been considered a future super star [14].

In this paper we report the identification of four different wood species using an electronic nose formed by an array of 


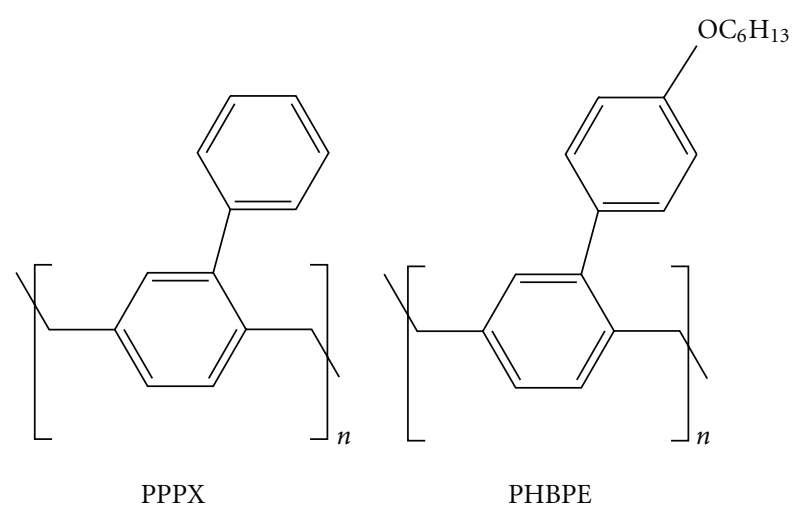

(a)

(b)

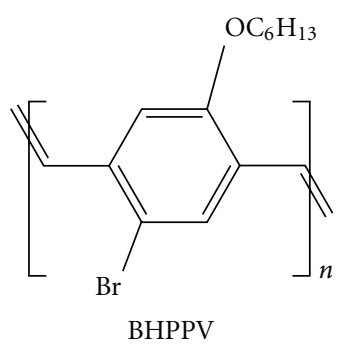

(c)

Figure 1: Chemical structures of the conductive polymers used for assembling the sensors.

three chemiresistive sensors based on conductive polymers (Figure 1) and also the recognition and discrimination of the same wood samples through the direct elemental emission of ten chemical elements determined by LIBS. It is worth to note that although the trees of these species can be easily identified by their shapes, branches, leaves, and flowers, this is no longer true once they have been chopped making it difficult to classify them just on simple inspection.

\section{Experimental}

2.1. Conductive Polymers. Poly(2-phenyl-1,4-xylylene) (PPPX), poly (4'-hexyloxy-2,5-biphenyleneethylene), (PHBPE), and poly(2-bromo-5-hexyloxy- $p$-phenylenevinylene) (BHPPV) were synthesized according to the literature procedures [15], [7] and [16], respectively.

2.2. Preparation of the Sensors. Solutions containing $2.5 \mathrm{mg}$ of each of the above polymers (PPPX, PHBPE, and BHPPV), $0.7 \mathrm{mg}$ of dodecylbenzenesulfonic acid (DBSA) and $0.7 \mathrm{~mL}$ of chloroform were prepared. Then, polymer films of $\sim 1 \mu \mathrm{m}$ thickness were deposited by spin coating $40 \mu \mathrm{L}$ of these solutions onto interdigitated electrodes, previously prepared by conventional lithography, having an interdigitated area of $1 \mathrm{~cm}^{2}$ and $20 \mu \mathrm{m}$ gaps between digits (Figure 2).

2.3. Wood Samples. Samples of Cedrela (Cedrela fissilis) and Brazilian walnut (Ocotea porosa) were obtained from the

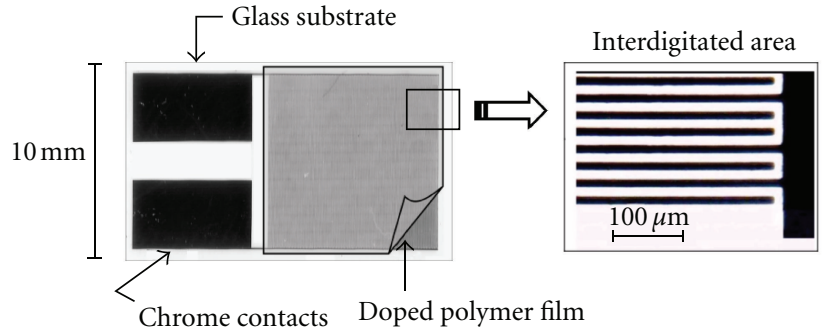

FIgURE 2: Structure of the interdigitated polymeric sensor.

Botanical Department of the Instituto de Biociências da Universidade de São Paulo. Angelim (Hymenolobium petraeum) and Perobinha (Aspidosperma subincanum) samples were obtained from the Madeiras Pinheiro Ltda. These samples were cut into parallelepipeds measuring $3.0 \mathrm{~cm} \times 3.0 \mathrm{~cm} \times$ $1.5 \mathrm{~cm}$ each (total surface of $36 \mathrm{~cm}^{2}$ ) and stored in separate hermetically sealed plastic bags. Just before each experiment, the samples were sandpapered in order to expose the volatile compounds.

2.4. E-Nose Measurements. A pneumatic assembly for dynamic sampling, as shown in Figure 3, was used for the measurements. Thus, the sensors were exposed to the headspace of each wood sample, kept at $30^{\circ} \mathrm{C}$, for $5 \mathrm{~s}$ (exposure period; valves 1 and 2 open, valve 3 closed), then to dry air for $35 \mathrm{~s}$ (recovery period; valves 1 and 2 closed, valve 3 open). The airflow was maintained constant at $0.5 \mathrm{~L} \mathrm{~min}^{-1}$. The tests were repeated ten times for each of the four samples. The conductance of the sensors was continuously monitored with accurate conductivity meters [17], operating with $80 \mathrm{mV}$ peak-to-peak $2 \mathrm{kHz}$ triangle wave $\mathrm{AC}$ voltage and connected via a 10 bit analog to digital converter to a personal computer.

2.5. LIBS Measurements. Experiments were performed with a Q-switched Nd:YAG laser (Brilliant, Quantel, France) at $1064 \mathrm{~nm}$, generating $5 \mathrm{~ns}$ pulses of $(365 \pm 3) \mathrm{mJ}$ in a $6 \mathrm{~mm}$ diameter beam with quality factor M2 smaller than 2 , at $10 \mathrm{~Hz}$ repetition rate. The laser pulses were focused on the wood sample by a convergent lens with $2.54 \mathrm{~cm}$ diameter and $20 \mathrm{~cm}$ focal length (Edmund Optics, USA). The plasma emission was collected by a telescope composed of $50 \mathrm{~mm}$ and $80 \mathrm{~mm}$ focal length fused silica lenses (LLA, Germany) and coupled to the spectrometer optical fiber $(1.5 \mathrm{~m}, 600 \mu \mathrm{m}$ core). The telescope collection angle with respect to the laser optical axis was $25^{\circ}$. A model ESA 3000 spectrometer (LLA Instruments $\mathrm{GmbH}$, Germany) with the Echelle optics and focal length of $25 \mathrm{~cm}$, which provides a $24.5 \times 24.5 \mathrm{~mm}^{2}$ flat image plane, was used. The detector is an ICCD camera, comprised of a Kodak KAF 1001 CCD array of $1024 \times$ 1024 pixels full frame $\left(24 \times 24 \mu \mathrm{m}^{2}\right)$ and a microchannel plate image intensifier of $25 \mathrm{~mm}$ diameter coupled to a UVenhanced photocathode. The image signals are digitalized in dynamic range of 16 bits and further computer processed. The dark current of the ICCD was automatically subtracted from the measured spectral data. The selection of LIBS operating conditions was consisted on 30 laser pulses per 


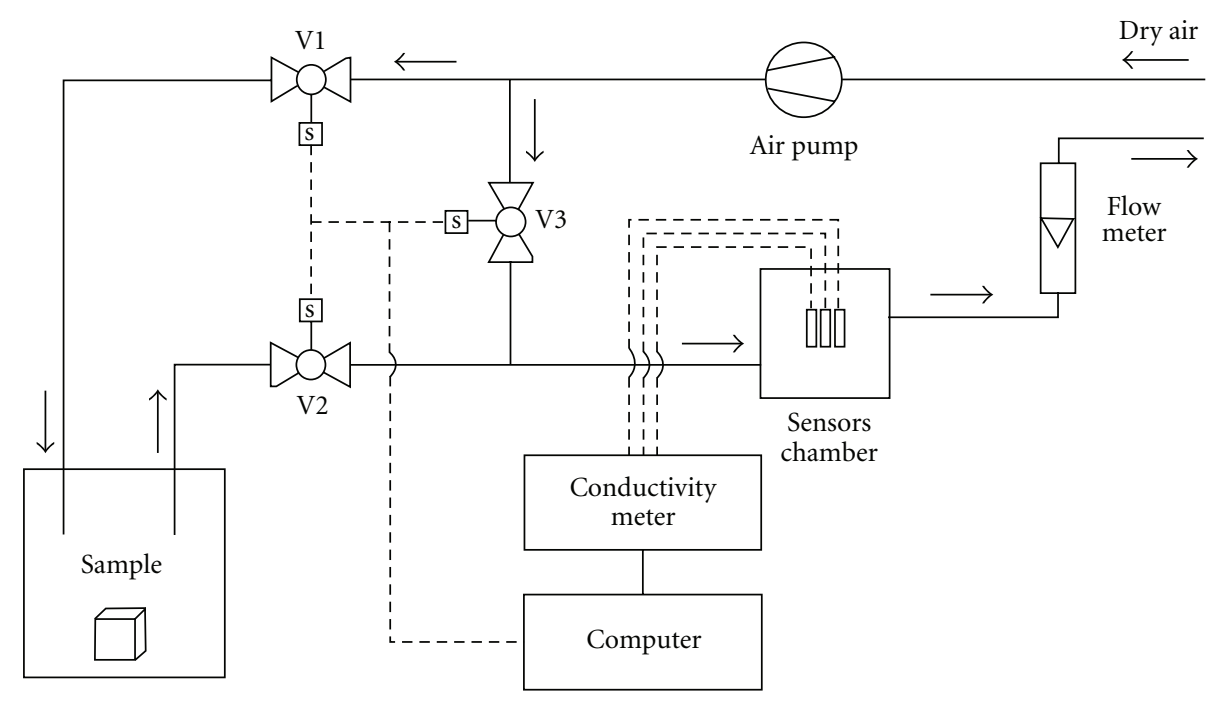

FIGURE 3: Setup of the e-nose measuring system.

site, $300 \mathrm{~mJ}$ per pulse, $17.5 \mathrm{~cm}$ lens-to-sample distance, $5 \mu \mathrm{s}$ integration time gate, and $2 \mu$ s delay time.

The same wood samples reported at the e-nose measurements were used for the LIBS measurements. The sample was placed in the sample holder of the ablation unit, which was assisted by a two-axe manually controlled translation stage that moved in the plane orthogonal to the laser direction and using the same procedure described elsewhere [13]. The spectral regions were selected $(\mathrm{Al}(\mathrm{I})=308.216 \mathrm{~nm}, \mathrm{~B}(\mathrm{I})=$ $249.773 \mathrm{~nm}, \mathrm{Ca}(\mathrm{II})=422.673 \mathrm{~nm}, \mathrm{Cu}(\mathrm{I})=324.775 \mathrm{~nm}$, $\mathrm{Fe}(\mathrm{II})=259.940 \mathrm{~nm}, \mathrm{Mg}(\mathrm{I})=277.983 \mathrm{~nm}, \mathrm{Mn}(\mathrm{II})=$ $257.610 \mathrm{~nm}, \mathrm{Na}(\mathrm{I})=589.592 \mathrm{~nm}, \mathrm{P}(\mathrm{I})=253.560 \mathrm{~nm}$, and $\mathrm{Zn}(\mathrm{I})=206.200 \mathrm{~nm})$.

2.6. Chemometrics. Principal component analyses (PCA) were performed using Statistica 10.0 (StatSoft Inc., USA). Leave-one-out analysis was performed using DimReduction (GNU) [18]. The analyses were carried out using, separately, the relative responses $(\mathrm{Ra})=\left(G_{\max }-G_{o}\right) / G_{o}$, where $G_{\max }$ is the maximum conductance and $G_{o}$ is the initial conductance of the sensors values, and emission measurements at the wavelength reported in Section 2.4 without any prior preprocessing and scaling as the input of the mathematical algorithms.

All data were recorded in triplicate for each independent sample in a random order. For the LIBS experiments, each replicate represented the mean of ten measurements performed for each sample in different parts of the wood (total of 30 measurements per sample).

\section{Results and Discussion}

3.1. E-Nose. Three different polymers were used to compose the array of gas sensors. Both PPPX and PHBPE are poly $(p-$ xylylene) derivatives that contain small conjugated units (biphenyls) and BHPPV is a poly(p-phenylenevinylene) derivative. All the polymers bear side groups that enhance solubility in organic solvents, which is an important feature for film processing. Doping with dodecylbenzenesulfonic acid (DBSA), a Lewis acid with good miscibility with the polymers, was performed to produce electrically conductive films deposited by spin coating onto interdigitated electrodes. It is worth mentioning that although there is no extended conjugation through the polymer chains of PPPX and PHBPE, the presence of the biphenyl units (six conjugated double bonds) ensures doping and electrical conductivity [19].

The change in conductance of the sensors was monitored during several cycles of exposure (sniff) to the headspace of wood samples confined in the sample chamber (Figure 3 ) followed by exposure to fresh dry air until complete recovery of the sensors. As can be seen in Figure 4, each sensor gave a different reversible response, both in shape and intensity, on exposure to a particular wood sample.

The relative responses $(\mathrm{Ra})$ were calculated for each cycle for all the sensors and woods and gathered in a data set formed by three columns ( $\mathrm{Ra} 1, \mathrm{Ra} 2, \mathrm{Ra} 3$ ) and 40 lines (ten cycles for each wood sample). A three-dimensional scatter plot of these data (Figure 5) revealed four separated clusters, one for each type of wood. It is worth to mention that a leaveone-out analysis [20] of this set of data gave a rate of hits of $100 \%$.

The sensors have been tested daily for over six months and still respond in the same way. This fact becomes even more relevant considering the total cost of each sensor, which is less than US\$10.

3.2. LIBS. The application of chemometric analysis to discriminate the wood species based on conductance measurements was clearly illustrated above. A second purpose of the work is try to use the $\mathrm{Al}, \mathrm{B}, \mathrm{Ca}, \mathrm{Mg}, \mathrm{Zn}, \mathrm{Cu}, \mathrm{Mn}, \mathrm{Fe}, \mathrm{Na}$, and $\mathrm{Si}$ emission measurement obtained by LIBS to evaluate 


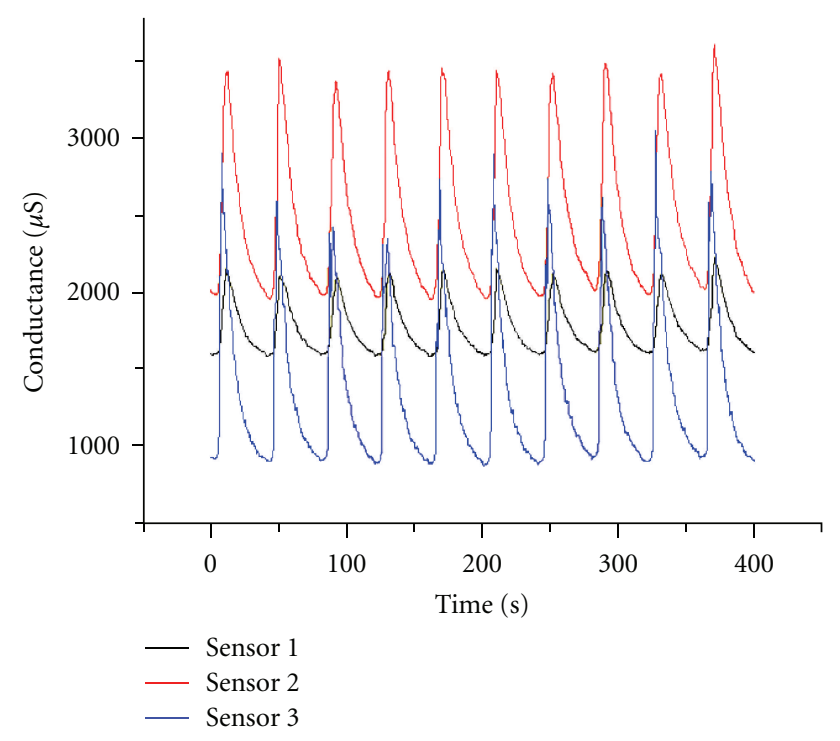

FIGURE 4: Response of the sensors to ten cycles of exposure/recovery to the volatile compounds of Brazilian walnut (Ocotea porosa) at $30^{\circ} \mathrm{C}$. Sensor $1=\mathrm{PPPX}$, sensor $2=\mathrm{PHBPE}$, and sensor $3=\mathrm{BHPPV}$, all doped with CSA.

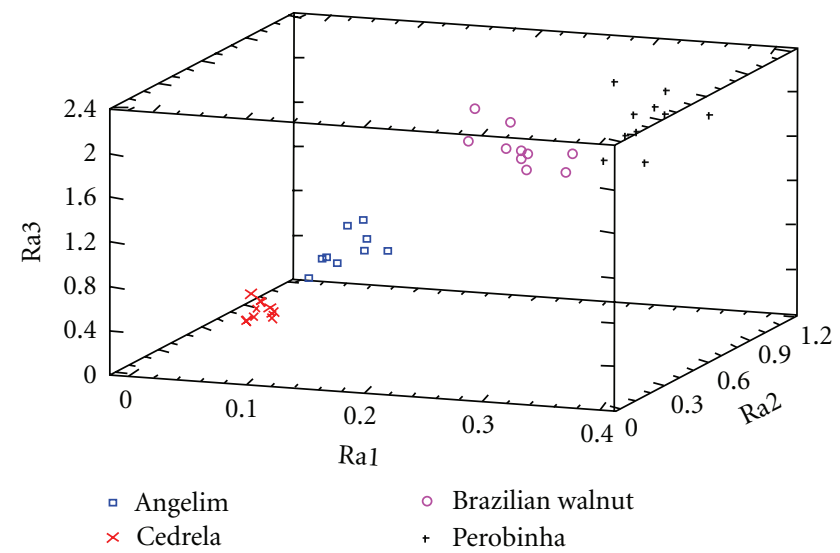

FIGURE 5: Plot of the relative responses $(\mathrm{Ra})$ of the three sensors.

similarities and differences between these four wood species studied previously.

For PCA, a model was obtained using three principal components (PCs), which explained up to $97.19 \%$ of variance between the four samples analyzed. The PC1, PC2, and PC3 are responsible for 44.91, 26.31, and 25.97\% of the variance, respectively. The differentiation between the samples or the variables can be seen in the scores and the loadings graphics (Figures 6 and 7, resp.). In Figure 6, four clusters were obtained, each cluster in one quadrant. The analysis of the loading plots revealed that the variables responsible for the classification of the woods are the emission intensities of $\mathrm{Fe}, \mathrm{Na}, \mathrm{Si}$, and $\mathrm{Al}$ for Angelim; B for Perobinha; Ca for Cedrela; $\mathrm{Cu}, \mathrm{Zn}, \mathrm{Mn}$, and $\mathrm{Mg}$ for Brazilian walnut.

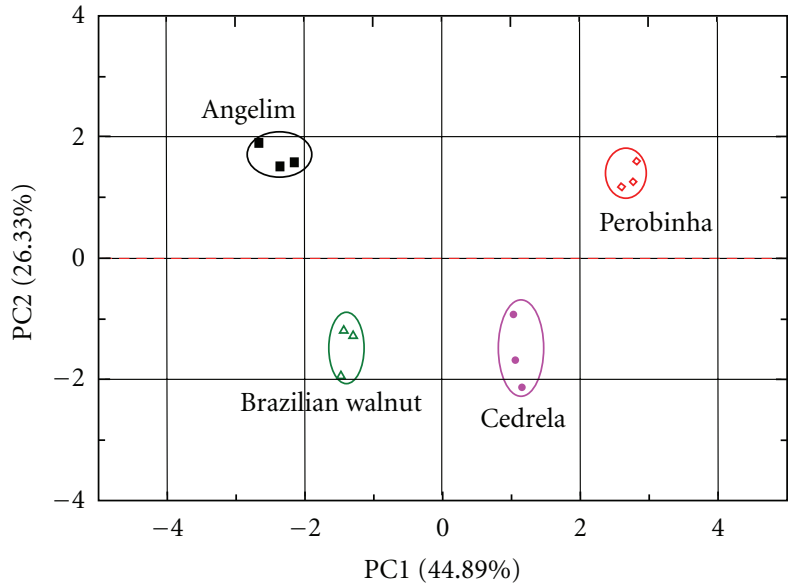

FIGURE 6: Bidimensional principal component analysis of the four wood species by LIBS.

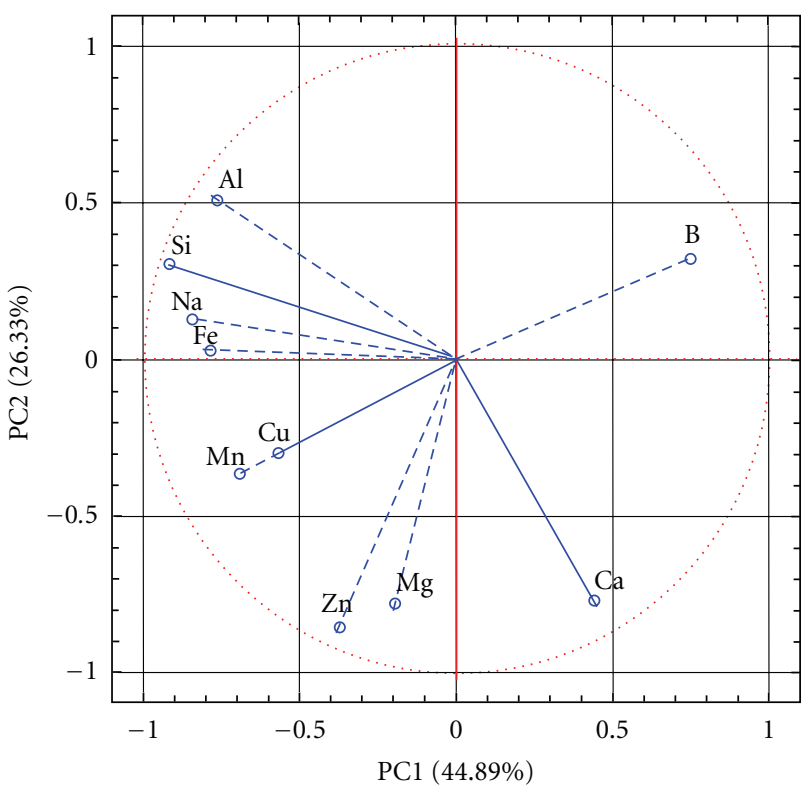

FIGURE 7: Bidimensional loading plots of the variables analyzed by LIBS in Figure 6.

\section{Conclusions}

A low-cost conductive polymer-based portable electronic nose formed by an array of only three gas sensors was very efficient (100\% rate of hits) in the identification of four different Brazilian commercial woods: Cedrela (Cedrela fissilis), Brazilian walnut (Ocotea porosa), Angelim (Hymenolobium petraeum), and Perobinha (Aspidosperma subincanum).

The same wood samples could be also perfectly identified by laser-induced breakdown spectrometry (LIBS), measuring the emission of ten elements: $\mathrm{Al}, \mathrm{B}, \mathrm{Ca}, \mathrm{Mg}, \mathrm{Zn}, \mathrm{Cu}, \mathrm{Mn}$, $\mathrm{Fe}, \mathrm{Na}$, and $\mathrm{Si}$. 
Both methods may be of great help in the protection of endangered wood species, since they can be used in loco and present short analysis time.

\section{Acknowledgments}

The authors thank the Conselho Nacional de Desenvolvimento Científico e Tecnológico (CNPq) (Grants 303717/ 2010-6 and 140721/2010-0) and Fundação de Amparo à Pesquisa do Estado de São Paulo (FAPESP) (Grant 2009/078591) for the financial supports. Thanks are due to Dr. Marcelo N. P. Carreño and to Dr. Gustavo P. Rehder for producing the interdigitated electrodes, to Dr. Gregório C. T. Ceccantini for stimulating discussions and for providing some of the wood samples, and to Ms. Renata Lippi and Mr. Carlos H. A. Esteves for drawing Figures 2 and 3, respectively.

\section{References}

[1] G. A. O’Neill, I. Dawson, C. Sotelo-Montes et al., "Strategies for genetic conservation of trees in the Peruvian Amazon," Biodiversity and Conservation, vol. 10, no. 6, pp. 837-850, 2001.

[2] C. F. Gouvêa, M. C. Dornelas, and A. P. Martinelli, "Characterization of unisexual flower development in the endangered mahogany tree Swietenia macrophylla King. (Meliaceae)," Botanical Journal of the Linnean Society, vol. 156, no. 4, pp. 529535, 2008.

[3] T. C. M. Pastore, J. W. B. Braga, V. T. R. Coradin et al., "Near infrared spectroscopy (NIRS) as a potential tool for monitoring trade of similar woods: discrimination of true mahogany, cedar, andiroba, and curupixá," Holzforschung, vol. 65, no. 1, pp. 73-80, 2011.

[4] R. M. Rosa, R. L. Szulc, R. W. C. Li, and J. Gruber, "Conducting polymer-based chemiresistive sensor for organic vapours," Macromolecular Symposia, vol. 229, pp. 138-142, 2005.

[5] M. S. Meruvia, I. A. Hümmelgen, C. S. Gonçalves, A. R. V. Benvenho, and J. Gruber, "Ferrocene-based copolymer for the sensing and discrimination of low-molecular-weight alcohols," Sensor Letters, vol. 5, no. 3-4, pp. 625-628, 2007.

[6] L. O. Péres, R. W. C. Li, E. Y. Yamauchi, R. Lippi, and J. Gruber, "Conductive polymer gas sensor for quantitative detection of methanol in Brazilian sugar-cane spirit," Food Chemistry, vol. 130, no. 4, pp. 1105-1107, 2012.

[7] R. W. C. Li, L. Ventura, J. Gruber, Y. Kawano, and L. R. F. Carvalho, "A selective conductive polymer-based sensor for volatile halogenated organic compounds (VHOC)," Sensors and Actuators B, vol. 131, no. 2, pp. 646-651, 2008.

[8] A. R. V. Benvenho, R. W. C. Li, and J. Gruber, "Polymeric electronic gas sensor for determining alcohol content in automotive fuels," Sensors and Actuators B, vol. 136, no. 1, pp. 173176, 2009.

[9] J. W. Gardner and P. N. Bartlett, Electronic Noses_Principles and Applications, Oxford University Press, New York, NY, USA, 1999.

[10] J. Naozuka, M. A. M. S. da Veiga, E. M. Richter, T. R. L. C. Paixão, L. Angnes, and P. V. Oliveira, "Use of Metals and Anion Species with Chemometrics Tools for Classification of Unprocessed and Processed Coconut Waters," Food Analytical Methods, vol. 4, no. 1, pp. 49-56, 2011.

[11] F. R. S. Bentlin, F. H. Pulgati, V. L. Dressler, and D. Pozebon, "Elemental analysis of wines from South America and their classification according to country," Journal of the Brazilian Chemical Society, vol. 22, no. 2, pp. 327-336, 2011.

[12] C. Turra, E. A. N. Fernandes, M. A. Bacchi, F. S. Tagliaferro, and E. J. França, "Differences between elemental composition of orange juices and leaves from organic and conventional production systems," Journal of Radioanalytical and Nuclear Chemistry, vol. 270, no. 1, pp. 203-208, 2006.

[13] Q. Godoi, F. O. Leme, L. C. Trevizan et al., "Laser-induced breakdown spectroscopy and chemometrics for classification of toys relying on toxic elements," Spectrochimica Acta B, vol. 66, no. 2, pp. 138-143, 2011.

[14] J. D. Winefordner, I. B. Gornushkin, T. Correll, E. Gibb, B. W. Smith, and N. Omenetto, "Comparing several atomic spectrometric methods to the super stars: special emphasis on laser induced breakdown spectrometry, LIBS, a future super star," Journal of Analytical Atomic Spectrometry, vol. 19, no. 9, pp. 1061-1083, 2004.

[15] R. W. C. Li, L. R. F. Carvalho, L. Ventura, and J. Gruber, "Low cost selective sensor for carbonyl compounds in air based on a novel conductive poly( $p$-xylylene) derivative," Materials Science and Engineering C, vol. 29, no. 2, pp. 426-429, 2009.

[16] A. R. V. Benvenho, R. Lessmann, I. A. Hümmelgen et al., "Physical and chemical characterization of poly(2-bromo-5hexyloxy-p-phenylenevinylene) and poly $\left(5,5^{\prime}\right.$-dibromo- $2,2^{\prime}$ bis-hexyloxy-4, 4' -biphenylenevinylene) - comparison to related polymers," Materials Chemistry and Physics, vol. 95, no. 1, pp. 176-182, 2006.

[17] R. T. Da Rocha, I. G. R. Gutz, and C. L. Do Lago, "A lowcost and high-performance conductivity meter," Journal of Chemical Education, vol. 74, no. 5, pp. 572-574, 1997.

[18] 2011, http://sourceforge.net/projects/dimreduction/.

[19] J. Gruber and R. W. C. Li, "Electrochemical synthesis of poly $(4,4$ '-biphenylene ethylene)s," European Polymer Journal, vol. 36, no. 5, pp. 923-928, 2000.

[20] F. M. Lopes, D. C. Martins, and R. M. Cesar, "Feature selection environment for genomic applications," BMC Bioinformatics, vol. 9, article 451, 2008. 


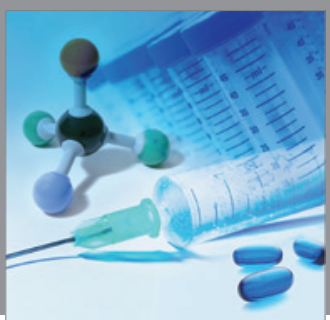

International Journal of

Medicinal Chemistry

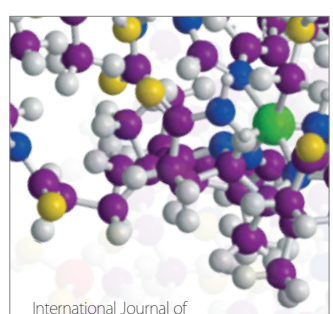

Carbohydrate Chemistry

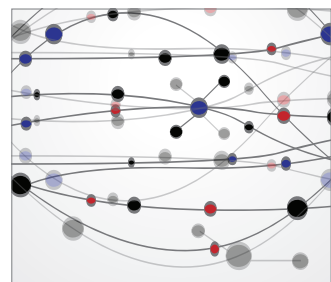

The Scientific World Journal
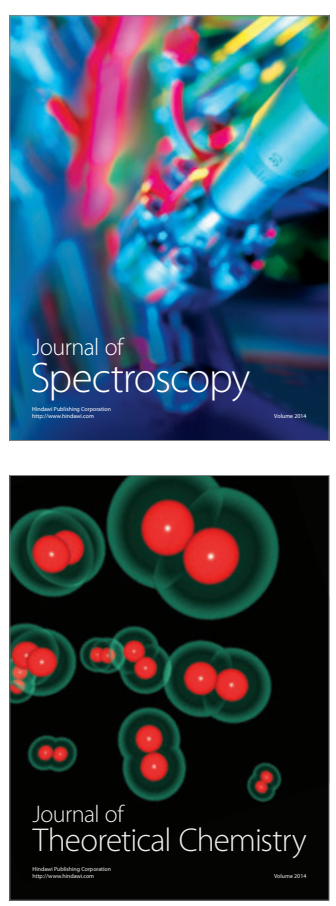
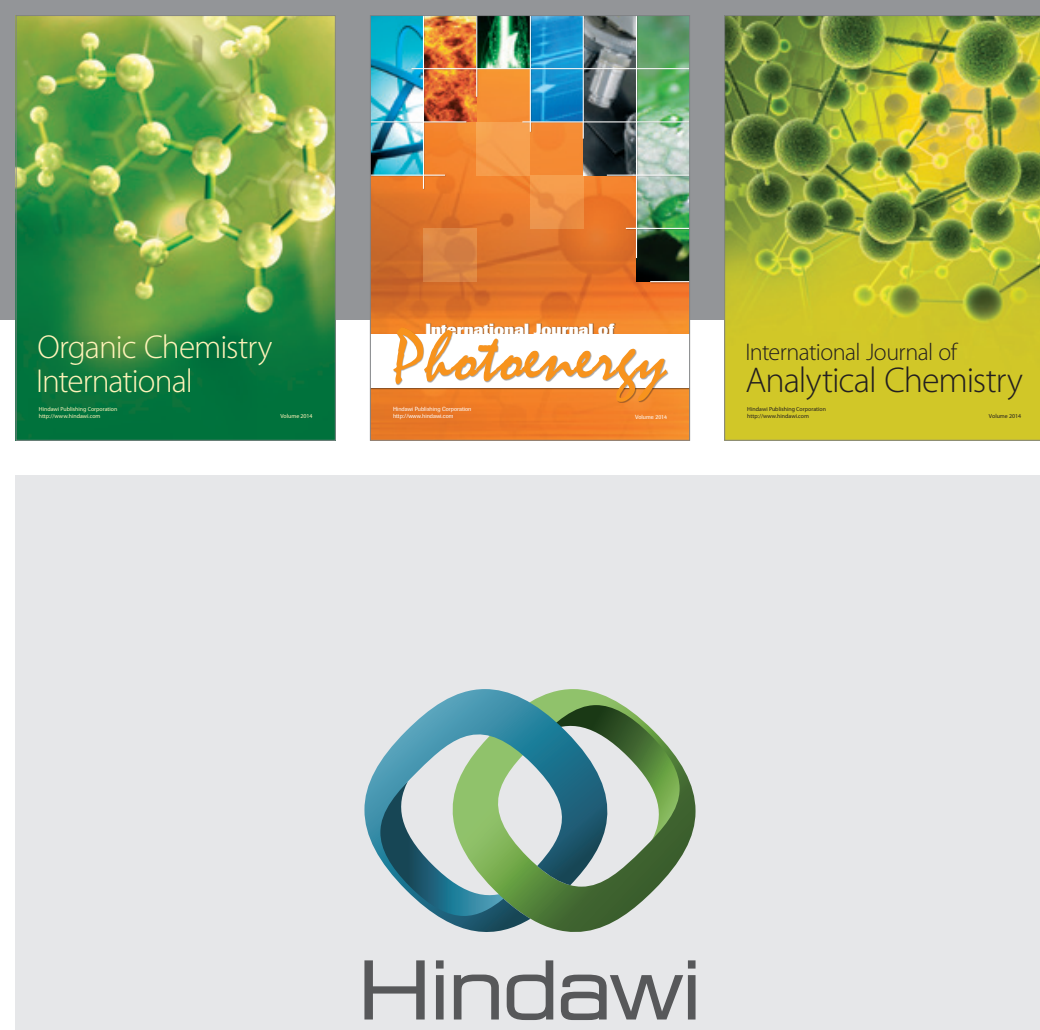

Submit your manuscripts at

http://www.hindawi.com
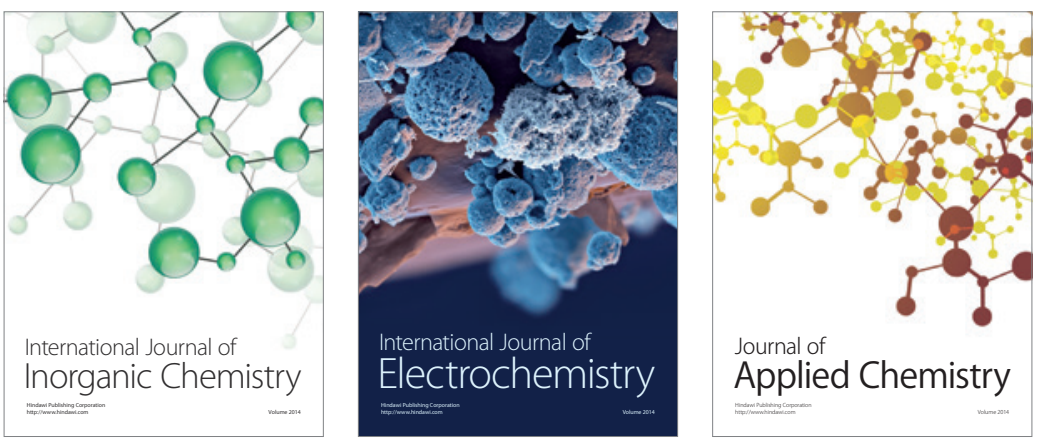

Journal of

Applied Chemistry
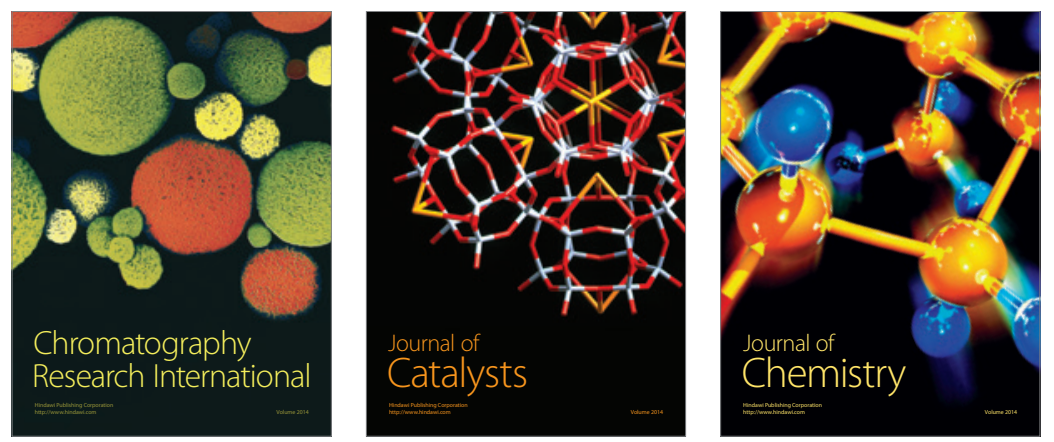
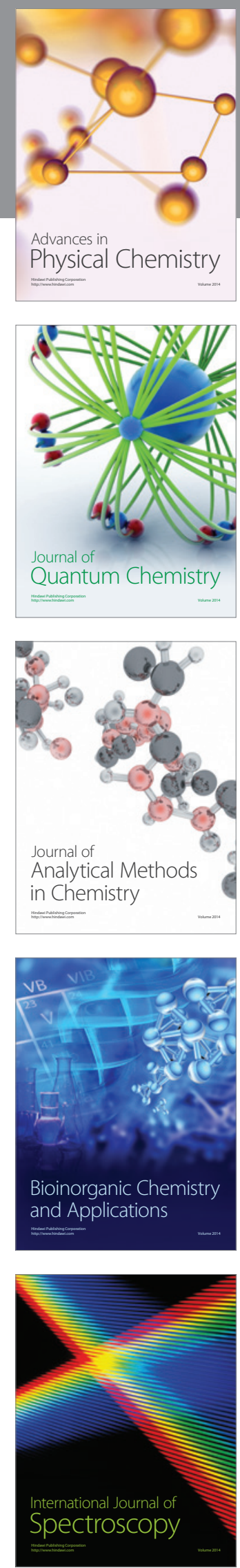